\title{
Young individuals with stroke: a cross sectional study of long-term disability associated with self-rated global health
}

\author{
Susanne Palmcrantz ${ }^{1 *}$, Lotta Widén Holmqvist ${ }^{1,2}$ and Disa K Sommerfeld ${ }^{1,3,4}$
}

\begin{abstract}
Background: Perceived disability after stroke may persist long-term even among young individuals with mild stroke and may be related to age-related expectations of health and recovery. Thus, in order to appreciate the magnitude of perceived disability in a younger stroke population studies are needed to explore perceived health-related differences between young individuals with stroke and a matched general population. Further, to provide long-term measures by health care, relevant to the same young individuals with stroke, their perceived long-term functioning and disability associated with health need to be explored.
\end{abstract}

Methods: The generic questionnaire EQ-5D was used to compare ratings of global health and disability between young individuals living in the community up to 6 years after stroke $(n=150)$ and an age and geographically matched general population $(n=2661)$. Stroke related medical data were retrieved from medical records and the study specific questionnaire, the MYS-questionnaire, was used to assess self-rated disability associated with global health.

Results: Among the young individuals $79 \%$ had suffered a mild stroke, $45 \%$ rated a low global health compared to $15 \%$ of the matched general population and a higher proportion rated problems in mobility, self-care, usual activities and anxiety/depression. Among the young individuals with stroke, limitations and restrictions in leisure activities, work, reading as well as low level of physical activity, utilizing personal care provider or personal assistance and tiredness were negatively associated with self-rated global health (R square 0.60).

Conclusion: The negative effects of stroke, on self-rated global health among young individuals living in the community, appear to be substantial, multi factorial and long-standing which call for interdisciplinary research collaborations and team measures by health care long-term.

Keywords: Community, Disability, Health, Stroke, Young

\section{Background}

Health has been defined as comprising physical, mental and social aspects [1] as well as demands of life that commensurate with contextual factors such as age, culture and personal responsibility [2]. Among individuals with stroke, perceived disability involving various aspects included in these definitions of health, has been shown to persist long term after stroke [3-5]. In stroke populations, the International Classification of Functioning, Disability and Health (ICF) has been found to be

\footnotetext{
* Correspondence: susanne.palmcrantz@ki.se

'Division of Physiotherapy, Department of Neurobiology, Care Sciences and Society, Karolinska Institutet, Huddinge, Stockholm, Sweden

Full list of author information is available at the end of the article
}

favorable when used to map this diversity of aspects of functioning and disability associated with health [6]. The ICF has a body, individual and societal perspective and comprise various dimensions of health including the components body functions, body structures, activity, participation and contextual factors that are both personal and environmental [7]. Notably, in the total stroke population, individuals of working age $(<65$ years $)$ are a minority and may deviate from the majority in expectations on functioning and health that commensurate with age related goals and expectations on recovery e.g. return to work [8-10]. These expectations may also be related to the nature of the national health and welfare system as well as the demands that are placed on the

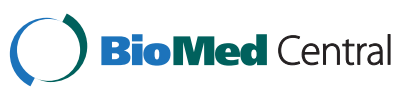


individual in their community and social life. Using a global rating of health, a recent Swedish study [5] finds that among individuals with stroke, disability in terms of limitations in mobility, and domestic life and mental impairments explain approximately half of the variance in self-rated health after stroke. However, in qualitative studies of individuals with stroke living in the community, younger individuals express more concerns about, e.g. returning to work while older individuals express difficulties more related to physical impairments, e.g. walking and difficulties in leaving the house, driving a car and using public transport $[9,11,12]$. Thus, in order to appreciate the magnitude of perceived disability in a younger stroke population, studies are needed to explore perceived health-related differences between young individuals with stroke and a matched general population. Further, to provide long-term measures by health care, relevant to the same young individuals with stroke, their perceived longterm functioning and disability associated with health need to be explored.

The aims of the study were to:

- explore differences between young individuals with stroke and a matched general population in long-term self-rated global health, functioning and disability

- explore aspects of long-term functioning and disability associated with self-rated global health in the same young individuals with stroke

\section{Methods}

All young individuals of working age (18-64 years) were eligible for the study if they: 1) had been admitted to Södersjukhuset (Stockholm South General Hospital) Stockholm, Sweden, when suffering a stroke during 2000-2006, 2) had been registered in the Swedish Stroke Register (Riks-Stroke) [13], 3) were registered residents in the south of Stockholm and 4) were not institutionalized or living in sheltered accommodation at the time of the survey. Stroke related medical data in terms of stroke diagnosis according to the ICD-10 classification [14], stroke severity according to the Scandinavian stroke scale (SSS) classified as being mild, moderate or severe [15,16], lateralization, time for onset, sex, as well as diagnosed risk-factors for stroke (previous stroke, hypertension, hypercholesterolemia, cardiac arrhythmia, diabetes mellitus) were obtained from the hospital medical records.

In January 2007 a Swedish questionnaire consisting of 59 questions aiming to map young persons with stroke (the MYS questionnaire [17]) and the EQ-5D questionnaire [18] were distributed to 232 young individuals with stroke [19].

Prior to the present study the MYS questionnaire was constructed and tested in terms of content validity by an expert group and in terms of face validity, readability and stability by young individuals with stroke [17]. The
MYS questionnaire was found to be valid thus, covering relevant aspects of functioning and disability among a selected sample of young individuals with stroke $(n=15)$ who were interviewed in a sampling to redundancy process [17]. The MYS-questionnaire was found to be stable (the test-retest agreement was overall fair to very good (kappa 0.44-1.0)) with the exception of 2 questions and 1 alternative answer which were not included in the present study [17]. Results on long-term health-states derived from the MYS questionnaire have previously been classified according to the components of the ICF and presented [19]. Included in the present study were:

1) impaired body functions (tiredness, memory, concentration, irritability, initiative, sleep, appetite, self-reported depression, stress, anxiety, bursting into tears in everyday situations, pain and impaired swallowing) were rated as impaired when experienced often/constantly and not impaired when experienced almost never/sometimes

2) limitations and restrictions in activity and participation (need of assistance in eating/drinking, toileting, caring for body parts, dressing, moving around indoors, moving around outdoors, using public transport, cooking, cleaning, shopping, economic transaction, and experienced limitations and restrictions in speaking, reading, writing, calculating, leisure activities and work) were rated as present or not.

3) personal factors (age, sex, educational level [ $\leq$ senior high school or university level education], smoking or not, low or moderate/high level of physical activity [with a cut off for low physical activity set at $\leq 1$ hour of moderately strenuous activities/week]).

4) environmental factors (living alone, not experienced support from significant other, experienced dependence on significant other, receiving assistance from personal care provider or personal assistant, not receiving stroke related checkups by a physician, not experienced sufficient current rehabilitation) were rated as present or not.

EQ-5D is a generic measure used to assess health outcome and contains a quantitative measure that assesses perceived global health rated on a vertical, visual analogue scale (EQ VAS) which is calibrated with the anchors "worst imaginable health-state" (0) and "best imaginable health state" (100) [18]. Further, the EQ-5D includes 5 self-classifier health-state dimensions (EQ-5D dimensions): mobility, self-care, usual activities, pain/discomfort and anxiety/depression. Each EQ-5D dimension is graded according to the alternative statements: no problems, some problems or extreme problems. The measure is found to be valid and reliable and has been used in public surveys $[18,20]$. Evidence of construct validity has been 
found in comparisons with the SF-36 and the VAS has been found to be reliable in test retest (ICC 0.78) in general populations $[18,20]$. The EQ-5D has also been found to be valid and reliable in stroke-populations. In test of construct validity, increasing dysfunction reported with the EQ-5D domains has been found to be associated with lower scores on the standard instruments used to assess stroke outcome $\mathrm{p}<0.0002$ and in test-retest in a stroke population, a kappa ranging from 0.63 to 0.80 has been reported [21-23].

Comparative normative EQ-5D data were retrieved from an age (range) and geographically matched reference group in the general population [24]. This group had filled in the questionnaire approximately 6 months before the distribution of the EQ-5D questionnaires to the young individuals with stroke.

The study was approved by the Regional Ethical Review Board in Stockholm. Informed consent was obtained from the respondents to the questionnaires.

\section{Statistics}

The t-test was used to assess differences between the young individuals with stroke and the matched general

\begin{tabular}{l} 
Table 1 Characteristics of the young individuals with \\
stroke including stroke related medical factors and \\
personal factors $(\mathbf{n}=150)$ \\
\hline $\mathrm{n}$
\end{tabular}

\begin{tabular}{|c|c|c|}
\hline & $\mathbf{n}$ & $\%$ \\
\hline $\begin{array}{l}\text { Age: median } 59 \text { years }\left(I \mathrm{QR}^{\mathrm{a}} \text { 54-62;); }\right. \\
\left.\text { mean } 57 \text { years ( } \mathrm{SD}^{\mathrm{b}} 6\right) \text {; range } 32-64\end{array}$ & - & - \\
\hline Women & 50 & 33 \\
\hline Infarction/hemorrhage/not specified & $120 / 26 / 4$ & $80 / 17 / 3$ \\
\hline Hemisphere: left/right/not specified & $77 / 63 / 10$ & $51 / 42 / 7$ \\
\hline Stroke severity: mild/moderate/severe & $119 / 19 / 12$ & $79 / 13 / 8$ \\
\hline Hypertension & 69 & 46 \\
\hline Hypercholesterolemia & 27 & 18 \\
\hline Previous stroke & 26 & 17 \\
\hline Diabetes mellitus & 21 & 14 \\
\hline Cardiac arrhythmia & e12 & 8 \\
\hline 6 years $^{c}$ & 19 & 13 \\
\hline 5 years $^{c}$ & 18 & 12 \\
\hline 4 years $^{c}$ & 15 & 10 \\
\hline 3 years $^{c}$ & 23 & 15 \\
\hline 2 years $^{c}$ & 22 & 14 \\
\hline 1 year $^{c}$ & 32 & 21 \\
\hline 3 months to 1 year $^{c}$ & 21 & 15 \\
\hline University level education & 53 & 35 \\
\hline Smoking & 49 & 33 \\
\hline Low level of physical activity ${ }^{d}$ & 38 & 25 \\
\hline
\end{tabular}

${ }^{a}$ Inter quartile range, ${ }^{b}$ Standard deviation ${ }^{\mathrm{C}}$ Years since stroke onset ${ }^{\mathrm{d}} \leq 1$ hour of moderately strenuous activities/week.
Table 2 The number of young individuals with rated disability and reported environmental factors $(n=150)$

\begin{tabular}{lll}
\hline Disability & $\mathbf{n}$ & \% \\
\hline Impairment & & \\
Tiredness & 67 & 45 \\
Concentration & 34 & 23 \\
Irritability & 32 & 21 \\
Memory & 30 & 20 \\
Initiative & 30 & 20 \\
Pain & 28 & 19 \\
Stress & 28 & 19 \\
Anxiety & 27 & 18 \\
Self-reported depression & 27 & 18 \\
Sleep & 26 & 17 \\
Bursting into tears in everyday situations & 15 & 10 \\
Impaired swallowing & 10 & 7 \\
Appetite & 8 & 5
\end{tabular}

Activity limitation and participation restriction

$\begin{array}{lr}\text { Leisure activities } & 85 \quad 57\end{array}$

$\begin{array}{lr}\text { Work } & 5939\end{array}$

$\begin{array}{lll}\text { Writing } & 46 & 31\end{array}$

$\begin{array}{llll}\text { Cleaning } & 40 & 27\end{array}$

$\begin{array}{lll}\text { Shopping } & 37 \quad 25\end{array}$

Economic transaction $\quad 35 \quad 23$

Reading $\quad 33 \quad 22$

$\begin{array}{lll}29 & 19\end{array}$

Speaking $\quad 27 \quad 18$

$\begin{array}{lll}\text { Calculating } & 27 \quad 18\end{array}$

Using public transport $\quad \begin{array}{ll}17 & 11\end{array}$

Moving around outdoors $\quad \begin{array}{lll}16 & 11\end{array}$

Caring for body parts $\quad 139$

Dressing $13 \quad 13$

Moving around indoors $\quad 4 \quad 3$

Eating/drinking $\quad 3 \quad 2$

Toileting $\quad 3 \quad 2$

Environmental factors $\quad$ n $\%$

\begin{tabular}{ll}
\hline Not receiving stroke related checkups & $74 \quad 50$
\end{tabular}

Living alone $\quad 65 \quad 43$

Dependence on significant other $\quad 51 \quad 34$

No support from significant other $\quad 3926$

Not sufficient current rehabilitation $\quad 3926$

Receiving assistance from personal care provider or personal $\quad 24 \quad 16$ assistant

population with regard to self-rated global health (the EQ VAS). To determine the number of younger persons with stroke who rated a low global health a cut off was 
set by subtracting $1 \mathrm{SD}$ from the mean ratings of global health in the matched general population. The alternative statements to the EQ-5D dimensions were dichotomized into no disability (no problems) and disability (moderate to severe problems). The Chi-squared test was used to analyze differences in the rated EQ-5D dimensions between the groups.

Four multiple linear regression analyses were performed using the following health-states from the MYS questionnaire as independent variables: 1 ) body functions and impairments, 2) activity, participation and limitations and restrictions, 3) personal factors and, 4) environmental factors. A $5^{\text {th }}$ multiple linear regression analysis was performed by entering all significant independent variables in analyses 1-4 in a final model. In each of the analyses the dependent variable was self-rated global health (the EQ VAS). In addition 1 multiple linear regression analysis was performed using the stroke related medical factors known at stroke onset (type, lateralization, mild or moderated/severe stroke and diagnosed risk factors for stroke) as independent variables. All analyses were controlled for sex and time since stroke onset. A significant level was set at $\mathrm{p}<0.05$ and a stepwise method was used. An adjusted R-square explaining the variance by $0-0.25$ was considered little to poor, $0.25-0.50$ fair, $0.50-0.75$ moderate and $\geq 0.75$ very good to excellent [25].

\section{Results}

Of the 232 young individuals with stroke 150 individuals (65\%) filled in and returned the MYS and the EQ-5D questionnaires. The characteristics of the young individuals with stroke including stroke related medical factors and personal factors are presented in Table 1. The young individuals' ratings of disability and reported environmental factors are presented in Table 2. A majority (79\%) had suffered a mild stroke. Normative EQ-5D data was retrieved from 2661 geographically and age (range) matched individuals in the general population (median 46 years, inter quartile range $38-55$ and 54\% women). The young individuals with stroke rated significantly lower global health (mean 63, SD 24) than the matched general population (mean 79 , SD 18) $(p<0.000)$. Fortyfive percent $(n=67)$ of the young individuals with stroke as opposed to $15 \%(\mathrm{n}=392)$ in the general population rated low global health. The distribution of ratings in the EQ-5D dimensions is presented in Table 3. When differences between groups were explored significantly more individuals with stroke rated disability according to the EQ-5D dimensions: mobility, self-care, usual activities and anxiety/depression. No significant difference between groups was found in the EQ-5D dimension regarding pain/discomfort.

Table 3 The distribution of individual ratings according to the EQ-5D self-classifier dimensions presented for young individuals with stroke (YWS) $(n=150)$ and an age and geographically matched general population $(\mathrm{GP})(\mathrm{n}=2661)$

\begin{tabular}{|c|c|c|c|c|c|c|c|c|c|}
\hline Dimension & YWS\% & GP\% & $p$ & YWS women & GP women & $p$ & YWS men & GP men & $\mathbf{p}$ \\
\hline \multicolumn{10}{|l|}{ Mobility } \\
\hline No problem & 60 & 91 & & 64 & 91 & & 57 & 91 & \\
\hline \multirow[t]{2}{*}{ Moderate/severe problem } & 40 & 9 & & 36 & 9 & & 43 & 9 & \\
\hline & & & $<0.0000$ & & & 0.0004 & & & $<0.0000$ \\
\hline \multicolumn{10}{|l|}{ Self care } \\
\hline No problem & 83 & 98 & & 85 & 98 & & 82 & 97 & \\
\hline \multirow[t]{2}{*}{ Moderate/severe problem } & 17 & 2 & & 15 & 2 & & 18 & 3 & \\
\hline & & & 0.0003 & & & 0.0010 & & & 0.0005 \\
\hline \multicolumn{10}{|l|}{ Usual activities } \\
\hline No problem & 72 & 90 & & 73 & 89 & & 71 & 91 & \\
\hline \multirow[t]{2}{*}{ Moderate/severe problem } & 28 & 10 & & 27 & 11 & & 29 & 9 & \\
\hline & & & 0.0012 & & & 0.0039 & & & 0.0003 \\
\hline \multicolumn{10}{|l|}{ Pain/discomfort } \\
\hline No problem & 48 & 56 & & 44 & 52 & & 50 & 60 & \\
\hline \multirow[t]{2}{*}{ Moderate/severe problem } & 52 & 44 & & 56 & 48 & & 50 & 40 & \\
\hline & & & 0.2575 & & & 0.2575 & & & 0.1552 \\
\hline \multicolumn{10}{|l|}{ Anxiety/depression } \\
\hline No problem & 47 & 64 & & 38 & 61 & & 51 & 67 & \\
\hline \multirow[t]{2}{*}{ Moderate/severe problem } & 53 & 36 & & 62 & 39 & & 49 & 33 & \\
\hline & & & 0.0156 & & & 0.0011 & & & 0.0214 \\
\hline
\end{tabular}


Results of the 5 linear multiple regression analyses that explored the association between self-rated functioning and disability (assessed with the MYS questionnaire) and self-rated global health (EQ VAS) among the younger individuals with stroke are presented in Table 4. Sex and time since stroke onset were not associated with selfrated global health in any of the analyses. In the final model, health-states from the MYS questionnaire explained $60 \%$ of the variance in self rated global health. The main contributing factors were limitations and

Table 4 Results of the 5 linear multiple regression analyses exploring self-rated functioning and disability (assessed with the MYS questionnaire) that were associated with self-rated global health (EQ VAS) among the younger individuals with stroke

\begin{tabular}{llll}
\hline$B^{\mathrm{a}}$ & $95 \% \mathrm{Cl}^{\mathrm{b}}$ & $\mathrm{p}$ & $\begin{array}{l}\text { Adjusted } \\
\text { R square }\end{array}$ \\
\hline
\end{tabular}

1. Impairments

Tiredness

Initiative

Depression

Pain

$\begin{array}{llll}-12.3 & -19.6 & -5.0 & 0.001 \\ -11.5 & -20.4 & -2.7 & 0.011 \\ -12.2 & -21.5 & -2.9 & 0.010 \\ -10.2 & -19.1 & -1.3 & 0.026\end{array}$

2. Activity limitations and Participation restrictions

Leisure activities

Work

Reading

Cleaning

$\begin{array}{llll}-15.6 & -21.9 & -9.3 & 0.000\end{array}$

$\begin{array}{llll}-11.3 & -17.5 & -5.1 & 0.000\end{array}$

$\begin{array}{llll}-14.0 & -21.6 & -6.4 & 0.000\end{array}$

$\begin{array}{llll}-11.0 & -18.1 & -3.9 & 0.003\end{array}$
3. Personal factors

Low physical activity

$\begin{array}{llll}-21.2 & -29.6 & -12.9 & 0.000\end{array}$

4. Environmental factors

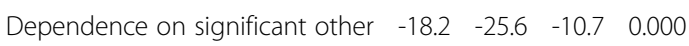

Personal assistance ${ }^{c}$

$\begin{array}{llll}-20.2 & -30.1 & -10.3 & 0.000\end{array}$

5. Final model ${ }^{\mathrm{d}}$

Leisure activities

Work

$\begin{array}{llll}-14.3 & -20.5 & -8.2 & 0.000\end{array}$

$\begin{array}{llll}-11.7 & -17.5 & -6.0 & 0.000\end{array}$

Reading

Low physical activity

Personal assistance ${ }^{c}$

Tiredness

$\begin{array}{llll}-10.2 & -17.6 & -2.7 & 0.008\end{array}$

$\begin{array}{llll}-10.8 & -16.8 & -4.9 & 0.000\end{array}$

$\begin{array}{llll}-10.8 & -18.8 & -2.9 & 0.008\end{array}$

$\begin{array}{llll}-7.6 & -13.6 & -1.6 & 0.013\end{array}$

The independent variables which were the main contributors to explain the variance in self-rated global recovery are presented first and thereafter in descending for each analysis.

${ }^{a}$ Regression coefficient, ${ }^{b}$ Confidence Interval, ${ }^{c}$ Utilizing personal care provider or personal assistance, ${ }^{\mathrm{d}}$ Including all significant independent variables in models 1-4. restrictions in return to previous leisure activities and not having returned to work which were negatively associated with self-rated global health.

In the multiple linear regression analysis including stroke related medical factors known at stroke onset, only stroke severity was associated with self-rated global health (B -19.254, CI 95\% -28.553 to $-9.956, \mathrm{p}<0.000$, Adjusted R square 0.10 ) rated 3 months to 6 years after stroke onset.

\section{Discussion}

This study found lower ratings of health among young individuals with stroke compared to a matched general population in Sweden. Although 79\% of the young individuals had suffered a mild stroke, $45 \%$ rated a low global health compared to the matched general population. Thus, in this younger stroke population in Sweden, a substantial negative impact of stroke on self-rated health was found. In addition, with a moderate explanatory level of $60 \%$ and supported by the literature presented below, we may conclude that relevant multi factorial aspects that negatively influence global health long-term were targeted. These aspects included limitations and restrictions in leisure activities and work, negatively associated with global health and have previously been found to be the most commonly reported aspects of disability in young individuals with stroke $[19,26]$. Performing leisure activities has been found to be a way of coping among young individuals after stroke [27] and not being able to return to work has been found to be associated with lower ratings of physical health [28]. Thus, return to leisure activities and work need to be in focus in rehabilitation planning. Factors influencing return to work involves not only impairments following stroke but also personal and environmental factors emphasizing the need for individualized measures [29]. Nonetheless, the beneficial effect of vocational rehabilitation has yet to be established thus further research is needed [30]. Moreover, limitation and restriction in reading was negatively associated with global health. Reading difficulties after stroke may be due to impaired mental functions such as impaired memory, concentration or language functions. Additionally, visual impairments have been found to be a common cause of reading difficulties and are treatable with assistive devices [31]. Thus, visual impairments should not be neglected in long-term assessments by health-care. Further, low physical activity was negatively associated with global health. Lack of information about, and fear of physical exertion have been reported among young individuals with stroke [32], and a dose response between physical activity and cardiovascular disease has been found [33]. Thus physical activity is a matter that needs to be targeted in long-term health care measures after stroke [34]. The negative association between utilization of a personal care provider or a personal 
assistant and self-rated global health found in the present study may be due to experienced lack of independence [35]. However, dissatisfaction with the assistance given may also be involved [36]. The effects of stroke are multi factorial which points to the necessity of stroke specific training for personal care providers and assistants.

Furthermore, tiredness was negatively associated with global health. Tiredness experienced often or constantly has been commonly reported [19]. Moreover, tiredness defined as fatigue has been found to be associated with disability and low ratings of general health among young individuals with stroke [37]. Further, as fatigue has been found to be negatively associated with return to work after stroke [38], we may assume that fatigue is a major concern long-term. A recent study demonstrates promising results in treating long-term fatigue by means of cognitive and graded physical activity training as well as by teaching compensation strategies [39]. Treatment for stroke related fatigue is a matter that needs to be explored in future studies.

This study has thus identified relevant aspects of global health that need to be targeted when long-term measures are allocated by the health-care system.

As more than $80 \%$ return home after stroke in Sweden [40], the young individuals in the present study who were all living in the community after stroke may be considered representative to young individuals with stroke. However, the study sample was limited and restricted to the capital of Sweden thus the representativeness may be questioned. Further, the results of the multiple linear regression analyses need to be interpreted with caution due to the width of the confidence intervals. Still, our findings, supported by the literature, indicate that presented health-states that were negatively associated with self-rated global health are long standing and commonly reported.

Notably none of the diagnosed risk factors were significantly associated with long-term self-rated global health. Further, although significantly associated, stroke severity at onset, poorly explained the variance in selfrated global health 3 months to 6 years after stroke. Instead, the long-term effects of stroke relevant to the young individuals often appear to be oriented toward mental impairments and activity limitations and participation restrictions $[27,41,42]$. Further, as a result of the validation process of the MYS questionnaire in which young individuals with stroke took part, the MYS questionnaire focuses on mental impairments and a majority of the questions deal with activity limitations and participation restrictions [17]. However, other aspects of disability have been reported as relevant among young individuals after stroke such as not being able to run a shorter distance [32] and depression of sexual activity [43]. These aspects could be considered in future studies of factors associated with self-rated global health.
We found no difference in the pain/discomfort dimension between the young individuals with stroke and the matched general population. Furthermore, similar ratings of pain/discomfort have been reported in a Swedish national survey including young individuals [20]. Notably, the occurrence of rated pain in the general population has been found to account for only half of the occurrence of rated pain/discomfort [44]. This finding indicates that there is a great difference between rated pain and rated pain/discomfort. Thus, future studies need to consider what these ratings of pain/discomfort incorporates as well as how the expression "discomfort" is interpreted by the rater.

\section{Conclusion}

The negative effects of stroke on self-rated global health found in the present study were substantial, longstanding and multi factorial among the young individuals with stroke living in the community. This disparity of factors that influence self-rated global health longterm reveals a need of multi professional assessments and measures by health-care in a long-term perspective, irrespective of initial stroke severity.

\section{Competing interests}

The authors declare that they have no competing interests.

\section{Authors' contributions}

SP performed the statistical analyses and is the first author. SP, LW and DS have made substantial contributions to design, analysis and interpretation of the data and LW and DS in commenting on the drafted manuscript. All authors read and approved the final manuscript.

\section{Sources of funding}

Financial support was provided through the regional agreement on medical training and clinical research (PickUp) between Stockholm County Council and Karolinska Institutet (KI), KID funding (KI faculty funds for partial financing of new doctoral student) and the Swedish stroke association; Stroke-Riksförbundet.

\section{Author details}

'Division of Physiotherapy, Department of Neurobiology, Care Sciences and Society, Karolinska Institutet, Huddinge, Stockholm, Sweden. ${ }^{2}$ Division of Neurology, Department of Clinical Neuroscience, Karolinska Institutet, Stockholm, Sweden. ${ }^{3}$ Department of Geriatric Medicine, Danderyd Hospital, Danderyd, Sweden. ${ }^{4}$ Department of Physical Therapy, Karolinska University Hospital, Stockholm, Sweden.

Received: 13 August 2013 Accepted: 27 January 2014

Published: 28 January 2014

\section{References}

1. World Health Organization: Program on mental health. Program on mental health. web site [http://www.who.int/mental_health/media/en/76.pdf].

2. Bircher J: Towards a dynamic definition of health and disease. Med Health Care Philos 2005, 8:335-341.

3. White JH, Alston MK, Marquez JL, Sweetapple AL, Pollack MR, Attia J, Levi CR, Sturm J, Whyte S: Community-dwelling stroke survivors: function is not the whole story with quality of life. Arch Phys Med Rehabil 2007, 88:1140-1146.

4. Teasdale TW, Engberg AW: Psychosocial consequences of stroke: A long-term population-based follow-up. Brain Inj 2005, 19:1049-1058. 
5. Alguren B, Fridlund B, Cieza A, Sunnerhagen KS, Christensson L: Factors associated with health-related quality of life after stroke: a 1-year prospective cohort study. Neurorehabil Neural Repair 2012, 26:266-274

6. Geyh S, Cieza A, Kollerits B, Grimby G, Stucki G: Content comparison of health-related quality of life measures used in stroke based on the international classification of functioning, disability and health (ICF): a systematic review. Qual Life Res 2007, 16:833-851.

7. Organization WH: The International Classification of functioning, disability and health (ICF). Geneva: WHO Library Cataloguing-in-Publication Data; 2001.

8. Ch'ng AM, French D, McLean N: Coping with the challenges of recovery from stroke: long term perspectives of stroke support group members. $J$ Health Psychol 2008, 13:1136-1146.

9. Roding J, Lindstrom B, Malm J, Ohman A: Frustrated and invisible-younger stroke patients' experiences of the rehabilitation process. Disabil Rehabil 2003, 25:867-874.

10. Medin J, Barajas J, Ekberg K: Stroke patients' experiences of return to work. Disabil Rehabil 2006, 28:1051-1060.

11. Vincent C, Deaudelin I, Robichaud L, Rousseau J, Viscogliosi C, Talbot LR, Desrosiers J: Rehabilitation needs for older adults with stroke living at home: perceptions of four populations. BMC Geriatr 2007, 7:20

12. Pound $P$, Gompertz $P$, Ebrahim S: A patient-centred study of the consequences of stroke. Clin Rehabil 1998, 12:338-347.

13. Riks-stroke, the Swedish Stroke Register. web site [http://www.riks-stroke.org]

14. World Health Organization: International Statistical Classification of Diseases and Related Health Problems 10th Revision Version. web site [http://www. who.int/classifications/icd/en/].

15. Multicenter trial of hemodilution in ischemic stroke-background and study protocol: Scandinavian stroke study group. Stroke 1985, 16:885-890.

16. Govan L, Langhorne P, Weir CJ: Categorizing stroke prognosis using different stroke scales. Stroke 2009, 40:3396-3399.

17. Palmcrantz SM, Holmqvist LW, Sommerfeld DK: Development, validity and reliability of a postal questionnaire assessing health states relevant to young persons with stroke in Sweden. Disabil Rehabil 2011, 33:1179-1185.

18. Brooks R: EuroQol: the current state of play. Health Policy 1996, 37:53-72.

19. Palmcrantz S, Holmqvist LW, Sommerfeld DK: Long-term health states relevant to young persons with stroke living in the community in southern Stockholm - a study of self-rated disability and predicting factors. Disabil Rehabil 2012, 34:817-823.

20. Burstrom K, Johannesson $M$, Rehnberg C: Deteriorating health status in Stockholm 1998-2002: results from repeated population surveys using the EQ-5D. Qual Life Res 2007, 16:1547-1553.

21. Dorman PJ, Waddell F, Slattery J, Dennis M, Sandercock P: Is the EuroQol a valid measure of health-related quality of life after stroke? Stroke 1997, 28:1876-1882

22. Pickard AS, Johnson JA, Feeny DH, Shuaib A, Carriere KC, Nasser AM: Agreement between patient and proxy assessments of health-related quality of life after stroke using the EQ-5D and Health Utilities Index. Stroke 2004, 35:607-612.

23. Dorman P, Slattery J, Farrell B, Dennis M, Sandercock P: Qualitative comparison of the reliability of health status assessments with the EuroQol and SF-36 questionnaires after stroke. United Kingdom Collaborators in the International Stroke Trial. Stroke 1998, 29:63-68.

24. The Stockholm County Council: Public health guide. web site [http://www. folkhalsoguiden.se/sv/Publikationer/470/465/Folkhalsorapporter-statistik/? ptitem $=63 \&$ cid $=333 \&$ saitem $=0$ ]

25. Colton T: Statistics in Medicine. Boston: Little Brown and Company; 1974.

26. Snogren M, Sunnerhagen KS: Description of functional disability among younger stroke patients: exploration of activity and participation and environmental factors. Int J Rehabil Res 2009, 32:124-131.

27. Carlsson GE, Moller A, Blomstrand C: Managing an everyday life of uncertainty-a qualitative study of coping in persons with mild stroke. Disabil Rehabil 2009, 31:773-782.

28. Vestling $M$, Tufvesson $B$, Iwarsson S: Indicators for return to work after stroke and the importance of work for subjective well-being and life satisfaction. J Rehabil Med 2003, 35:127-131.

29. Culler KH, Wang YC, Byers K, Trierweiler R: Barriers and facilitators of return to work for individuals with strokes: perspectives of the stroke survivor, vocational specialist, and employer. Top Stroke Rehabil 2011, 18:325-340.

30. Baldwin C, Brusco NK: The effect of vocational rehabilitation on return-towork rates post stroke: a systematic review. Top Stroke Rehabil 2011, 18:562-572.
31. Rowe F, Wright D, Brand D, Jackson C, Price A, Walker L, Harrison S, Eccleston C, Maan T, Scott C, et al: Reading difficulty after stroke: ocular and non ocular causes. Int J Stroke 2011, 6:404-411.

32. Roding J, Glader EL, Malm J, Eriksson M, Lindstrom B: Perceived impaired physical and cognitive functions after stroke in men and women between 18 and 55 years of age - a national survey. Disabil Rehabil 2009, 31:1092-1099.

33. Nocon M, Hiemann T, Muller-Riemenschneider F, Thalau F, Roll S, Willich SN: Association of physical activity with all-cause and cardiovascular mortality: a systematic review and meta-analysis. Eur J Cardiovasc Prev Rehabil 2008, 15:239-246.

34. Rincon F, Sacco RL: Secondary stroke prevention. J Cardiovasc Nurs 2008, 23:34-41. quiz 42-33.

35. Wood JP, Connelly DM, Maly MR: 'Getting back to real living': A qualitative study of the process of community reintegration after stroke. Clin Rehabil 2010, 24:1045-1056.

36. Asplund $K$, Jonsson F, Eriksson M, Stegmayr B, Appelros P, Norrving B, Terent A, Asberg KH: Patient dissatisfaction with acute stroke care. Stroke 2009, 40:3851-3856

37. Naess H, Waje-Andreassen U, Thomassen L, Nyland H, Myhr KM: Health-related quality of life among young adults with ischemic stroke on long-term follow-up. Stroke 2006, 37:1232-1236.

38. Andersen $\mathrm{G}$, Christensen D, Kirkevold M, Johnsen SP: Post-stroke fatigue and return to work: a 2-year follow-up. Acta Neurol Scand 2012, 125:248-253.

39. Zedlitz AM, Rietveld TC, Geurts AC, Fasotti L: Cognitive and graded activity training can alleviate persistent fatigue after stroke: a randomized, controlled trial. Stroke 2012, 43:1046-1051.

40. Riks-stroke: Swedish Stroke Register. web site [http://www.riks-stroke.org/ index.php?content=analyser].

41. Hofgren C, Bjorkdahl A, Esbjornsson E, Sunnerhagen KS: Recovery after stroke: cognition, ADL function and return to work. Acta Neurol Scand 2007, 115:73-80.

42. Hommel M, Miguel ST, Naegele B, Gonnet N, Jaillard A: Cognitive determinants of social functioning after a first ever mild to moderate stroke at vocational age. J Neurol Neurosurg Psychiatry 2009, 80:876-880

43. Neau JP, Ingrand P, Mouille-Brachet C, Rosier MP, Couderq C, Alvarez A, Gil R: Functional recovery and social outcome after cerebral infarction in young adults. Cerebrovasc Dis 1998, 8:296-302.

44. Bergman S, Herrstrom P, Hogstrom K, Petersson IF, Svensson B, Jacobsson LT: Chronic musculoskeletal pain, prevalence rates, and sociodemographic associations in a Swedish population study. J Rheumatol 2001, 28:1369-1377.

\section{doi:10.1186/1471-2377-14-20}

Cite this article as: Palmcrantz et al: Young individuals with stroke: a cross sectional study of long-term disability associated with self-rated global health. BMC Neurology 2014 14:20.

\section{Submit your next manuscript to BioMed Central and take full advantage of:}

- Convenient online submission

- Thorough peer review

- No space constraints or color figure charges

- Immediate publication on acceptance

- Inclusion in PubMed, CAS, Scopus and Google Scholar

- Research which is freely available for redistribution 